Estudios sobre armas antiguas, arte militar $\mathrm{y}$ vida cultural en oriente y occidente

XXXVI (2016), pp. 141-160

ISSN: 0436-029X

doi: 10.3989/gladius.2016.0007

\title{
LOS CASTILLOS MAYOR Y REAL DE LA CIUDAD DE CALATAYUD EN EL AÑO 1371 A LA LUZ DE DOS INVENTARIOS DEL ARCHIVO REAL
}

\author{
THE “MAYOR” AND “REAL” CASTLES OF THE TOWN OF CALATAYUD IN 1371 IN \\ THE LIGHT OF TWO INVENTORIES OF THE ROYAL ARCHIVE
}

POR

Álvaro Cantos Carnicer*

\section{RESUMEN - ABSTRACT}

Se analizan aquí dos interesantes inventarios de los objetos existentes en los Castillos Mayor y Real de Calatayud (Aragón) que fueron realizados en 1371. El estudio ha partido de la transcripción del texto original catalán del Archivo de la Corona de Aragón y se ha centrado en los elementos de arnés o armadura, armas e ingenios o máquinas de guerra; se ha indagado sobre el carácter y funcionalidad de cada objeto, así como en la terminología empleada, con aragonesismos patentes; se ha comparado en lo posible con textos coetáneos. El trabajo ha permitido conocer los elementos existentes en los castillos, determinando su especificidad, sus elementos, su estado, así como las carencias, no fácilmente explicables, como el caso de las ballestas. Por el contrario, la minuciosa descripción de las máquinas de guerra resulta verdaderamente excepcional.

The text shows the study of two interesting inventories mentioning the objects of two castles ("Mayor" and "Real") of Calatayud (Aragon), carried out in 1371. Firstly, the original text in Catalan of the Archive of the Crown of Aragon has been transcribed. The work is focused on the elements of armour, arms and artillery machines; the nature and function of every object have been researched, comparing, as far as possible, with other contemporary sources; the terminology has also been analysed and some evident Aragonese words have been found. This work has allowed to know the different elements existing in the castles, establishing their specificity, state and lacks, sometimes not easily explicable, as in the case of the crossbows. The meticulous description of the artillery machines is absolutely exceptional.

\section{Palabras Clave - Keywords}

Inventario; castillo; armas; arnés; armadura; artillería; ingenio; Archivo de la Corona de Aragón; catalán; aragonés; siglo XIV; Pedro IV; Calatayud; Aragón.

Inventory; castle; arms; armour; artillery machine; Archive of the Crown of Aragon; Catalan; Aragonese language; XIVth century; Peter IV; Calatayud; Aragon.

\section{INTRODUCCIÓN}

El presente artículo trata de analizar el contenido de dos inventarios de bienes muebles de los castillos Mayor y Real de Calatayud que fueron realizados el 26 y 27 de febrero de 1371 y que se hallan incluidos en uno de los volúmenes de Real Patrimonio, Maestre Racional, del

*alvarocantos@yahoo.es 
Archivo de la Corona de Aragón. ${ }^{1}$ Su transcripción figura en el apéndice final. Fueron elaborados por el notario público Pascual Asensio para registrar las armas y otros objetos que estaban en las fortalezas en ese momento. Bernat Arloví figura como funcionario real que cede estos objetos a los alcaides de los castillos, los cuales reconocen haberlos recibido.

Los inventarios, plasmados en sendas cartas públicas, fueron llevados al archivo real de Barcelona por Bernat Arloví y conservados en el cofre rojo de la oficina de Berenguer de Relat, Maestre Racional. Éste los trasladó al libro de "notaments comuns" en el que figuran. Están en catalán aunque con abundantes aragonesismos.

Los documentos se insertan en el período inmediatamente posterior a la Guerra de los dos Pedros. Durante parte de ésta, y en especial desde la reconquista aragonesa en 1366, los castillos Mayor y Real habían sido controlados por el rey, que había colocado en ellos a agentes reales o alcaides; en concreto, entre 1366 y 1368 se documenta al frente de los Castillos Mayor y Real a Jimeno Pérez de Rueda y Fortún de Corella, respectivamente ${ }^{2}$. Pero desde diciembre de 1370 la corona deja de dirigir las fortalezas en beneficio de las autoridades locales. ${ }^{3}$ Los inventarios reflejarían la entrega del contenido de los castillos por el rey a los nuevos alcaides que la ciudad había puesto al frente de las fortalezas. Para entonces había estallado ya una nueva crisis entre Aragón y Castilla, esencialmente en torno a la posesión de Molina, que supuso una escalada de tensión y el rearme de la zona fronteriza ${ }^{4}$. De hecho, al tiempo que se elaboraban los inventarios, el juez y procurador de los prohombres y la universidad de Calatayud, Andrés Gómez, prometía y juraba tener preparadas, cuando se moviera guerra en el Reino de Aragón, 500 fanegas de trigo o harina que deberían ser introducidas en los castillos Mayor y Real (300 fanegas en el primero y 200 en el segundo) cuatro días después de la publicación de la guerra en la ciudad; y lo mismo deberían hacer los jueces sucesivos. ${ }^{5}$

\section{EL INVENTARIO DEL CASTILLO MAYOR}

El Castillo Mayor se sitúa en el extremo septentrional de la ciudad y conserva interesantes restos de diversas cronologías (figura 1). Los alcaides del castillo eran a principios de 1371 Jaime Pérez de Azúa y Gil Martínez Civera, según indica el inventario. A continuación se irá pasando revista a los diversos elementos de éste, empezando por las piezas de armadura o indumentaria militar, siguiendo con las armas, las máquinas de guerra, y finalmente otros objetos.

Se mencionan cuatro yelmos de madera dorados y con las viseras de hierro, que sin duda se alejaban ya de los yelmos usuales en el siglo XIII, los cuales eran cilíndricos y cubrían totalmente la cabeza ${ }^{6}$ y aparecen representados por ejemplo en la techumbre de la catedral de Teruel (último tercio del siglo XIII) (figura 3). Curiosamente, los de Calatayud eran yelmos

1 Archivo de la Corona de Aragón [ACA], Real Patrimonio [RP], Maestre Racional [MR], Volúmenes, Serie General, 788, ff. 4v-6v. Di a conocer los inventarios en Cantos, 2012b (véanse las pp. 194, 218, 222, 227, 229, 230 y 233); un primer análisis en Cantos, 2014a: 15, 16, 22, 23; alguna mención suelta en Cantos, 2014b: 151 (molinos), 167-168 (máquinas de guerra).

2 Cantos, 2012a: 202-203; Cantos, 2014a: 8, 9, 10, 13.

3 Lafuente, 2009: 113; Cantos, 2014a: 14.

4 Sobre este conflicto: Zurita, 1967-1988, libro X, caps. V, VII, VIII, IX, X, XIV, XVII y XIX; Benítez Martín, 1992 (especialmente 18-33); Cantos, 2014a: 14-16.

5 ACA, RP, MR, Volúmenes, Serie General, 788, f. 6v (se refleja carta pública del notario Martín López del 27 de febrero de 1371).

6 Riquer, 1968: 35, 61 y 234. Véase también sobre los yelmos Bruhn de Hoffmeyer, 1982: 139 ss. 
de madera, por tanto algo rudimentarios, que estaban dorados (oripellats) ${ }^{7}$ y tenían cares de ferre, es decir, viseras de hierro. Está claro que deben ser diferenciados de otros elementos de protección de la cabeza como los sombreros de hierro y las capellinas ${ }^{8}$ (citadas más adelante en el inventario), así como de los bacinetes (véase figura 10), como ocurre en el inventario del alcázar de Teruel (1366); en éste se distingue entre éstos y los elms ab lurs viseres de ferra. ${ }^{9}$ Estos yelmos, aunque no se especifica que fueran de madera, serían parecidos a los de Calatayud: probablemente con cierre redondeado y prolongados hacia la nuca y las orejas, y dotados de visera, aunque sin la sofisticación del bacinete. ${ }^{10}$

Las capellinas citadas son tres, están hechas de hierro y se especifica que están rotas. El término capellina parece aplicarse a un casco semiesférico sin ala y por tanto muy sencillo, mientras que las palabras capacete y capell de ferro (sombrero de hierro; el casco más general en el siglo XIII en la Corona de Aragón) aludirían a cascos provistos de ala. ${ }^{11}$ La capellina se origina tal vez en el siglo XII y se sigue usando en el XIV ${ }^{12}$, siendo normal en Aragón durante la Guerra de los dos Pedros; formaba parte del equipo de los lanceros en las órdenes reales de agosto de 1361 a una serie de aldeas de Calatayud (debían tener "yelmo o capell o capellina de fierro") $)^{13}$.

Buenas representaciones de capellinas del siglo XIV se ven en las pinturas de Santa Lucía de Sos del Rey Católico (que Lacarra data en las primeras décadas del siglo XIV) ${ }^{14}$ (figura 7) o en las miniaturas de Las Cantigas de Santa María de Alfonso X en la segunda mitad del siglo XIII (figura 8). Ejemplos de capacetes se ven también en dichas pinturas (figura 7) y miniaturas (figura 4), así como en las pinturas de la torre del homenaje del castillo de Alcañiz, datables entre el último decenio del siglo XIII y el primero del XIV ${ }^{15}$ (figura 5) y en la puerta de San Ivo de la Catedral de Barcelona (datable hacia 1300) (figura 6).

En el inventario hay dos lorigones. El lorigón es un tipo de defensa corporal derivada de la loriga (túnica de mallas metálicas, o de cuero con escamas o anillos metálicos por encima, que cubría desde el cuello hasta las rodillas). ${ }^{16}$ En las fuentes castellanas, el lorigón sería una loriga corta (hasta mitad del muslo más o menos), con mangas que no pasaban del codo, y sin almófar (cubrición de mallas de la cabeza). ${ }^{17}$ El lorigón podía estar formado tanto por anillos

\footnotetext{
7 Estarían cubiertos de oropel (lámina de latón brillante como el oro); el latón es una aleación de cobre y cinc que se puede pulir hasta tener mucho brillo; Ramón Llull dice: "mesclen coure e lautó e donen los color e forma d'or e d'argent" (Alcover y Moll, 1978-1979, vol. VI: 915, voz "llautó"). En aragonés, tenemos la voz orpelados en un inventario zaragozano de 1393 (Serrano, 1917: 520).

8 Como se deduce de la orden de armamento a los habitantes de diversas aldeas de Calatayud en agosto de 1361, en que se habla de "yelmo o capell o capellina de fierro": ACA, Cancillería [Can.], registro [reg.]. 1469, ff. 21v-22r (Barcelona, 25-08-1361).

9 ACA, RP, MR, Volúmenes, Serie General, 784, f. 256r (véase también Lafuente, 2013: 153).

10 El yelmo con visera se cita ya en la crónica de Muntaner: Riquer, 1968: 60-61.

11 Respecto a capellinas y capacetes sigo lo dicho, por ejemplo, en Soler del Campo, 1993: 99. Algunos autores han mantenido, sin embargo, la idea de que la capellina era un casco con ala o borde grueso: Bruhn de Hoffmeyer, 1982: 147; Gago-Jover, 2002: 101-102. En lo referente al capacete, véase además: Almirante, 1989: 208; De Leguina, 1912: 203. Respecto al sombrero de hierro, véase Riquer, 1968: 36-37 y 61.

12 Se cita por ejemplo en las ordinaciones urbanas de Tortosa en 1341, así como en la carta de Pedro IV que en 1368 dispone el sueldo a recibir por la categoría armat de cors y en la descripción del armamento para los hombres a caballo según las cortes de Tarragona en 1370 (Riquer, 1968: 73, 86, 122).

13 ACA, Can., reg. 1469, ff. 21v-22r (Barcelona, 25-08-1361). Vése igualmente una referencia a la guarnición del castillo de Embid de Ariza en marzo de 1357: ACA, Can., reg. 1149, ff. 85v-86r (Zaragoza, 2-03-1357).

14 Lacarra, 1978: 496.

15 Rovira y Casanovas, 2014: 29-48 y 58.

16 Gago-Jover, 2002: 235; Bruhn de Hoffmeyer, 1982: 116 ss.; Almirante, 1989: 723.

17 Gago-Jover, 2002: 235-236; como indica este autor, la citada acepción de lorigón está recogida en las Siete partidas. Véase también: Almirante, 1989: 724; Bruhn de Hoffmeyer, 1982: 116; Soler del Campo, 1993: 119-121.
} 
de hierro como por pequeñas láminas o escamas. ${ }^{18}$ En el siglo XIII, las representaciones de Las Cantigas muestran la loriga usada especialmente por caballeros y el lorigón sobre todo por clases inferiores de guerreros (infantes, ballesteros, artilleros) (figuras 4 y 8); el lorigón aparece tanto solo como superpuesto a la loriga ${ }^{19}$ y podía ser cubierto por otra prenda.

No es extraña la presencia del lorigón en un inventario de fines del siglo XIV, dado que todavía entonces eran usuales las defensas de mallas o de escamas (lorigas y lorigones), aunque se complementaran con piezas de arnés de hierro. En la segunda mitad del siglo XIV se encuentran lorigones con mangas largas. ${ }^{20}$

En las fuentes catalanas medievales, loriga o lloriga designa las defensas de mallas del caballo y también las del hombre; la loriga castellana suele equivaler al ausberg (siendo el capmall la cubrición de la cabeza, equivalente al almófar castellano) pero también a la cota de malles y gonió. ${ }^{21}$ (Figuras 3, 7, 9, 10) En la Corona de Aragón, la palabra lorigó o lorigón aparece escasamente en comparación al ausberg. ${ }^{22}$ Aunque no existen más detalles sobre sus características concretas, está claro que el lorigón catalanoaragonés era una defensa de mallas utilizada al menos desde el siglo XIII al XV para la defensa del tronco y que pudo tener las características generales antes indicadas: más corta que la loriga o ausberg y normalmente con mangas cortas.

El inventario incluye también tres gorgueras o gorjales de hierro. La gorguera es una especie de collar rígido de hierro que protegía el cuello; el término catalán empleado en el documento es gorgera, que equivale a la gorgera, gorguera, gorjal o gola castellanos. ${ }^{23}$ El inventario del castillo de Sitges (1326) indica que también existían gorgueras de malla. ${ }^{24}$ La gorguera comienza a ser citada en la documentación catalanoaragonesa en el siglo XIII aunque de forma muy tímida (castillo de Villel) ${ }^{25}$, expandiéndose en los siglos XIV y XV. En la Guerra de los dos Pedros (1356-1369) la gorguera es usual y se le suele citar como accesorio de la coraza; en concreto, en documentos en aragonés vemos la expresión cuyraças con gorgeras o cuiraças con lures gorgeres. ${ }^{26}$ Uno de los testimonios iconográficos más interesantes lo constituye la escultura yacente de Àlvar de Cabrera, vizconde de Ager, datada entre 1299 y 1314, procedente de Bellpuig de les Avellanes (se halla actualmente en The Cloisters de Nueva York) (figura 9).

El inventario cita unos braçals (brazales) de hierro. Parece que las braceres y los braçals deben ser asimilados a los avantbraços o amambraços, piezas que cubrían el antebrazo, del codo al puño. ${ }^{27}$ Los dos primeros términos se usan en el siglo XIV mientras que los dos últimos serán frecuentes en las fuentes del XV. ${ }^{28}$ En aragonés, tenemos también la palabra "braçal". ${ }^{29}$

18 Bruhn de Hoffmeyer, 1982: 123-125.

19 Bruhn de Hoffmeyer, 1982: 123 y 137.

20 Bruhn de Hoffmeyer, 1982: 226, 228, 232, 240

21 Riquer, 1968: 232 y 235.

22 Riquer, 1968: 86; Miret i Sans, 1911: 64 (inventario de la casa templaria de Ambel); Sesma y Líbano, 1982: 244245 .

23 Alcover y Moll, 1978-1979, vol. VI: 340 (voz "gorgera"); Riquer, 1968: 73, 86, 235; Bruhn de Hoffmeyer, 1982 : 244-246; Almirante, 1989: 530; Soler del Campo, 1993: 134-135; Gago-Jover, 2002: 63, 200, 204-205.

24 Batlle y Parés, 1986: 170: se documenta una gorguera de láminas de hierro y otra de malla, así como 10 gorgueras moriscas.

25 En los inventarios de castillos catalanoaragoneses del Temple sólo en el de Villel se cita una goryera (Miret i Sans, 1911: 66).

26 ACA, Can., reg. 1384, f. 158r (Monzón, 20-12-1362); ACA, Can., reg. 1384, f. 159r (Monzón, 20-12-1362); ACA, Can., reg. 1385, ff. 64rv (Monzón, 20-12-1362) (Gutiérrez de Velasco, 1961: 15, notas 23 y 24; 16, nota 24).

27 Riquer, 1968: 81, 107, 108115 y 232.

28 Parece que en el siglo XIII no se habían desarrollado todavía las defensas de placas de hierro en los brazos, pues no se citan en los inventarios de castillos del Temple de hacia 1289; sin embargo, sí se citan abundantemente los ausbergs con capmall (Miret i Sans, 1911), formados por cotas de malla.

29 Serrano, 1915a: 343 (inventario de 1374, Zaragoza). 
En el aragonés del siglo XV se emplean las palabras brazalete, guardabrazos, guardabracos ${ }^{30}$ y avant-braços ${ }^{31}$ como equivalentes de las citadas catalanas.

Aparecen citados también dos pares de guants de launa (guanteletes), los cuales eran los guantes hechos de láminas de metal que protegían la mano, teniendo en cuenta que la launa es una lámina metálica delgada..$^{32}$ Otras expresiones usadas en la documentación catalana medieval son guantellet, guant de ferre, manyopa, guant, guant d'hacer o de malla. ${ }^{33}$ En Aragón, tenemos las voces guent de fierro (1374) y guant(e) de azero o de maylla. ${ }^{34}$ Las llaunes o launes (hojas delgadas de metal) cubrírían normalmente el exterior de los elementos de cuero, ya fuera yuxtapuestas o imbricadas..$^{35}$ Los antecedentes están en los guantes de malla, como los del inventario templario de Tortosa, de 1289 (se documentan varios parels de guans de ferre). ${ }^{36}$ Buenas representaciones de guants de launa o guanteletes, muy cercanas cronológicamente a los inventarios aquí analizados, aparecen en las tablas que representan la escena de la resurrección de Cristo del retablo de la Virgen del Monasterio de Sijena (1367-1381) (figura 10) y del retablo de la Resurrección del Monasterio de Canonesas del Santo Sepulcro de Zaragoza (1381-1382), ambos atribuidos a Jaime Serra.

En lo referente a la protección de la pierna, el inventario menciona, por una parte, dos pares de cameres (grebas) de hierro. El término camera es inusual en catalán medieval, prefiriéndose los términos gambera y cambera, que designan a la pieza de la armadura que servía para cubrir y defender la pierna del tobillo a la rodilla. La gambera, como las otras piezas de defensa de las piernas, aparece en el arnés catalanoaragonés en la segunda mitad del siglo XIII, como demuestra el inventario templario de Tortosa. ${ }^{37}$ Hacia 1300 se representa en el guerrero de la puerta de San Ivo de la catedral de Barcelona (figura 6). Magníficas representaciones de la segunda mitad del siglo XIV tenemos en las tablas de Sijena y Zaragoza, atribuidas a Jaime Serra, arriba citadas (figura 10). La gambera forma parte del arnès de cames señalado por Eiximenis (Dotzé del Chrestià, siglo XIV), junto con las cuixeres y las sabates de ferro. ${ }^{38} \mathrm{El}$ término camera, por el contrario, sí se emplea en el aragonés medieval y por tanto parece más bien un aragonesismo. ${ }^{39}$

Por otra parte, se advierte la mención de un par de cuxots (quijotes) y cameres (grebas) de cuero. Las voces medievales catalanas cuxot o cuixot, además de cuixera, cuxera y cuixal, designan a la pieza de la armadura que defendía el muslo y equivalen al "quijote" castellano; aparece a fines del siglo XIII, como demuestran los inventarios de las casas del Temple catalanoaragonesas. ${ }^{40}$ Tanto el término cuxot como cuxera son también aragoneses y se muestran en

30 Sesma y Líbano, 1982: 119 y 226. En 1521, el inventario del arzobispo Juan II menciona tanto la palabra bracal como guardabraço (Calahorra, 2000: 140).

31 Wittlin, 1976: 206.

32 El término launa (lámina delgada de metal) existe tanto en castellano como en catalán medieval; en catalán moderno se emplea la palabra llauna (Alcover y Moll, 1978-1979, vol. VI: 911, voz llauna).

33 Riquer, 1968: 76 y 81; 50 y 81; 107, 109 y 115.

34 Serrano, 1915a: 343; Sesma y Líbano, 1982: 226; en el inventario del palacio de los Zapata de Calatayud (1484) aparece la mención de "un guante de malla": Tomás Faci, 2009: 628; en un inventario turolense de 1484, "una guant de malla" (Wittlin, 1976: 206).

35 Riquer, 1968 : pp. 50 y 60.

36 Miret i Sans, 1911: 68.

37 Riquer, 1968: 34; Miret i Sans, 1911: 68.

38 Alcover y Moll, 1978-1979, vol. VI: 162 (voz “gambera”); Riquer, 1968: 76 y 80.

39 Sesma y Líbano, 1982: 130-131; con el mismo significado se utilizan los términos camal o quamal en aragonés. Serrano, 1915a: 343 (inventario de 1374): "Unas cameras de cuero"; Serrano, 1915b: 708 (inventario de 1369): "Cuxotes e cameras de cuero"; Serrano, 1917: 521: "Un cuxot et una camera".

40 Alcover y Moll, 1978-1979, vol., III : 830-832 (voces “cuixal”, “cuixera” y “cuixot”); Riquer, 1968: 34, 76, 80, 113, 115, 116 ; Miret i Sans, 1911: 66-69. En el inventario de Tortosa, la cita conjunta de la cuxera y del cuxot ("I pareyl de cuxeres et I pareyl de camberes et V cuxotz") permite sospechar que hubiera alguna diferencia entre ellas (ibidem, p. 68). 
la documentación entre los siglos XIII y XV. ${ }^{41}$ Las piezas del inventario de Calatayud son de cuero aunque, como en el apartado anterior, también podían ser de hierro.

Los elementos de protección de la pierna incluyen también un par de sabates de ferre (escarpes o zapatos de hierro). En la documentación catalana medieval, los zapatos de hierro son denominados sabates de ferre, sabatons o escarpes. En nuestro inventario son de hierro pero también podían ser de malla. ${ }^{42}$ Estos "zapatos de hierro" estarían formados por placas de hierro pero la sujeción del conjunto se realizaría mediante cuero interior y remaches externos. ${ }^{43}$

Para los zapatos de hierro vuelvo a remitir a las representaciones de los guerreros de la puerta de San Ivo de la catedral de Barcelona (figura 6) y los citados retablos de Sijena (figura 10) y Zaragoza; estos dos retablos muestran también los quijotes.

Dentro del apartado que podemos denominar estrictamente armas, el inventario cita sólo 25 escudos (escuts) con el símbolo de Santiago (ejemplos de escudos podemos ver en las figuras $3,4,6$ y 7) y un total de 271 cajas de viratones (aunque en el documento constan 270) con un total de 93.500 viratones (que resultan del recuento total, pese a que el documento indica que son 42.500). Los viratones eran saetas o dardos para ballesta (equivaldrían a los virotes, viras, cuadrillos y pasadores de otras fuentes); se indica que los genoveses eran de gran calidad.

Pasamos ahora al capítulo de las máquinas de guerra y sus accesorios (figuras 11-13). El comentario sobre estos elementos se realizará más adelante, en un capítulo específico, conjuntamente con los del Castillo Real. El inventario del Castillo Mayor menciona, por una parte, tres ginys (ingenios). El primero posee un escudo blanco; la perxa está sin acabar y faltan los clavos principales, la canal, 30 maderos del torno, todos los hierros pequeños, los parales ${ }^{44}$, las sogas o cuerdas y el pestillo de la caja. El segundo ingenio posee una bandera de Santiago $\mathrm{y}$ de él faltan todos los hierros pequeños y las sogas. El tercero es un ingenio pequeño que estaba dentro de la villa de Calatayud cuando estaba sitiada; tiene como símbolo una cruz; está preparado para tirar excepto por la ausencia de las sogas o cuerdas y los hierros pequeños.

Se mencionan asimismo dos trebuchs (trabucos). Uno de ellos fue llevado desde Villarroya; está completo, excepto por la carencia de las sogas o cuerdas, 10 maderos de la caja y los hierros pequeños. El otro trabuco se llama "del Zorzo" y falta de él lo siguiente: el pie y un hierro donde están las cajas, 10 maderos de las cajas, todos los hierros pequeños, las sogas y cuerdas y el torno con todos sus pertrechos.

Aunque incurre en contradicción, el inventario especifica que lo que falta en el último trabuco también falta en los ingenios y trabucos antes citados y que en todos ellos faltan asimismo todas las tablas de las cajas, clavijas, mazos, 3 pesas de pesar las piedras y los canales de los citados trabucos.

Se mencionan también como existentes una soga grande y una honda de cáñamo de ingenio, ambas nuevas, además de dos carros para llevar los ingenios (uno completo y el otro sólo con las ruedas).

El inventario contiene además diversos elementos no estrictamente militares. Por una parte, se citan recipientes para contener líquidos: 5 cubas o botas (recipientes de madera para guardar vino u otros líquidos), con sus aros (cercles) y, la mayoría, con sus orificios de entrada

41 Aparece en los inventarios de las casas templarias de Villel y Cantavieja, aunque en catalán (Miret i Sans, 1911: 66 y 67), en un inventario zaragozano de 1393 (Serrano, 1917: 520-521), en otro turolense de 1484 (Wittlin, 1976: 206: "Un par de cuxotes de tiempo antigo") y en el comercio medieval del siglo XV (Sesma y Líbano, 1982: 175).

42 Riquer, 1968: 76, 80, 113 y 116.

43 Soler del Campo, 1993: 147.

44 Desconozco el significado del término. 
y tapaderas (portes o cadiretes) ${ }^{45}$, puestos sobre serones; 2 tinas (recipientes troncocónicos de madera) con sus aros; una tina pequeña (tinell) sin aros. Se registran además tres molinos con sus muelas, nadillas y tolvas y uno con muelas pero sin hierros; la nadilla (que aparece como "vadilla" por error) es la pieza de hierro que transmitía el movimiento a la muela ${ }^{46}$ Hay también una contera para llevar una bandera y una cruz de hierro para la frente de un caballo.

\section{EL INVENTARIO DEL CASTILLO REAL}

El Castillo Real de Calatayud, también llamado del Picado, conserva sus restos, de planta alargada, algo al sur del Castillo Mayor (figura 2). Los alcaides del castillo eran a principios de 1371 Pedro Gilbert Bru y Andrés de Cevamanos, según nos indica el inventario. Éste incluye especialmente armas y máquinas de guerra.

Entre las armas hay que referirse por una parte a 4 venablos. El venablo es un dardo o lanza corta y arrojadiza ${ }^{47}$ No es palabra habitual en la documentación medieval catalanoaragonesa, siendo más frecuente dart o dardo.

En el Castillo Real había también 4 barras de glavis sin hierros. En las fuentes catalanoaragonesas el término glavi o glavis equivale a lanza. ${ }^{48}$ Las lanzas del inventario de Calatayud poseían sólo las astas, que serían de madera, y carecían de los hierros (barres de glavis sens ferres), que formarían la zona de la punta. ${ }^{49} \mathrm{El}$ término glavis designó también desde la segunda mitad del siglo XIV a los hombres de la caballería pesada (especialmente los provenientes de Francia), dado que la lanza era su arma ofensiva fundamental (paralelamente, comenzó a llamarse "lanzas" a las unidades de caballería pesada aragonesa). ${ }^{50}$ En cualquier caso, en la Corona de Aragón se prefieren las palabras lanza y dardo a glavis. ${ }^{51}$ Portan lanzas por ejemplo los jinetes de las pinturas de Santa Lucía de Sos (figura 7).

Los escudos mencionados en el inventario son 16, de los cuales 4 tienen el símbolo de Santiago; 5 son negros ${ }^{52}$; uno es blanco y tiene orla alrededor y una banda por en medio y 4 angelotes dorados; otro posee símbolo de veras ${ }^{53} \mathrm{y}$ dos castillos; 5 son de almacén. El escut (escudo o scudo en las fuentes aragonesas) como elemento defensivo debe ser diferenciado del pavés, que tenía forma alargada ${ }^{54} \mathrm{y}$ es muy frecuente en la documentación medieval de la

45 Alcover y Moll, 1978-1979, vol. II: 613, voz "bóta"; vol. II: 812, voz "cadireta"; vol. III: 796, voz "cuba”; vol. III: 123 y 124, voces "cercle" y "cèrcol"; vol. VIII: 767-768, voz "porta"; vol. X: 289, voz "tinell".

46 Alcover y Moll, 1978-1979, vol. VII: 689, voz "nadilla".

47 Alcover y Moll, 1978-1979, vol. X: 695, voz "venable"; De Leguina, 1912: 856; Gago-Jover, 2002: 351.

48 En el siglo XIV, los escritores catalanes Pere March y Eiximenis usan como sinónimos glavi y lança o llança (Riquer, 1968: 91; Bruhn de Hoffmeyer, 1982: 205 y 208).

49 Es frecuente en los inventarios reseñar si las lanzas tienen o no hierros: en Tous, se registran dos asters de glavi, la una ab ferre e l'altre meyns (Alós-Moner, 1910: 140); las tres lançes del inventario del alcázar de Teruel en 1366 poseían sus hierros (Lafuente, 2013: 153).

50 Lafuente, 2013: 137-138 y 148. Un ejemplo en marzo de 1363 cuando se cita la presencia de 1.000 caballeros y 500 glavis en el ejército de Enrique de Trastámara: ACA, Can., reg. 1385, f. 95v (Monzón, 5-03-1363) (véase Gutiérrez de Velasco, 1961: 19-20, nota 35).

51 En la citada orden de armamento de la población de ciertas aldeas de Calatayud, realizada en agosto de 1361, el grupo de lanceros debía incluir en su equipo "lança e dos dardos" (ACA, Can., reg. 1469, ff. 21v-22r; Barcelona, 25-081361); en el palacio Zapata de Calatayud había en 1484 "un fierro de lança” (Tomás Faci, 2009: 628).

52 La cantidad de escudos de este tipo no está clara en el texto original, al aparecer confusa la cantidad de barras del numeral; es posible que fueran cinco, porque así habría once escudos no de almacén, como dice el texto.

53 Pudo hacer referencia a la familia infanzona de los Vera, que tuvo ramas en Bordalba, Zaragoza, Calatayud, Ariza, Villarroya y Ayerbe; los Vera fueron señores de Vera de Moncayo y Pomer (Fernández Clemente, 1980-2007, t. XII, 1982: 3322).

54 De Leguina, 1912: 690. 
Corona de Aragón. ${ }^{55}$ También es usual, sin embargo, la palabra escut, escudo o scudo. ${ }^{56}$ Parece que en los documentos medievales catalanoaragoneses las palabras escudo y pavés son con frecuencia sinónimas, puesto que en las descripciones e inventarios suele aparecer sólo una de ellas y en alguna ocasión ambas palabras se unen con una conjunción disyuntiva (pavés $o$ escudo; pavezos ho scudos) ${ }^{57}$. Los escudos podían estar ornados con símbolos, pero también había algunos monocromos (en este caso oscuros: negres o morenos) y otros d'almatzem; la expresión "de almacén" designa en las fuentes medievales a los objetos normales, ordinarios, de poco valor, sin rasgos decorativos ${ }^{58}$.

Es mencionada asimismo una cajita con espinachs de ferre (abrojos). Los espinachs (o espinacs) de ferro son objetos de hierro de forma piramidal, con tres o cuatro puntas, de las cuales una queda hacia arriba en todas las posiciones; se colocaban en el suelo como elemento defensivo, especialmente contra la caballería enemiga ${ }^{59}$; equivalen a los abrojos y "cardos de hierro" en castellano ${ }^{60}$.

Las máquinas de guerra que aparecen en el inventario del Castillo Real son un trabuco, seis ginys y una cabrita. El trabuco (trebuch) tiene como marcas o símbolos 3 golpes y una deffra ${ }^{61}$ de carpintería; falta del trabuco todo el equipo del torno, las sogas o cuerdas, los hierros donde están las cajas y 5 maderos de las cajas.

El primer giny o ingenio citado tiene un símbolo o marca de estrella; faltan los hierros principales, las sogas o cuerdas necesarias, las clavijas, los otros clavos pequeños y las tablas de la caja. El segundo ingenio tiene por símbolos 3 golpes de escoplo ${ }^{62}$ y una llave (es decir, gatillo o disparador) de ballesta con una "O" en medio; le faltan ambos hierros principales y todos los demás hierros, clavijas y clavos pequeños, además de las sogas y cuerdas y todas las tablas de la caja. El tercer ingenio posee un escudo y en el centro una bandera de San Jaime; faltan el hierro de la caja, todos los demás hierros menudos, las sogas o cuerdas y todas las tablas de la caja. El cuarto ingenio tiene por símbolo un escudo con un lobo en el centro; faltan las clavijas, todos los hierros pequeños, todas las cuerdas y todas las tablas de la caja. El quinto ingenio tiene como símbolo una piña; faltan todos los clavos pequeños, las tablas de la caja, todas las clavijas y cuerdas. El último ingenio posee como símbolo un escudo en cuyo centro hay un símbolo de un ala; está por arreglar y reyatar y le faltan todas las clavijas, todos los clavos pequeños, todas las cuerdas y todas las tablas de la caja.

La cabrita tiene por símbolo dos hormas de zapato; todavía no está acabada de hacer y le faltan las cajas.

55 Por ejemplo, el pavés es el tipo de escudo citado en las acciones de aprovisionamiento de armas a Borja, Magallón y diversas fortalezas del sur de Aragón en diciembre de 1362 (Cella, Alba y Arcos) (ACA, Can., reg. 1385, ff. 64rv; ACA, Can., reg. 1384, f. 158rv; Monzón, 20-12-1362); también es citado en un inventario del castillo real de Daroca en 1454, con 12 ejemplares (Rodrigo, 1999: 76); en el castillo de Peñíscola había unos 65 paveses en 1451 (Betí, 1914: 95, 98 y 100).

56 Por ejemplo, en febrero de 1363 se realizaba la petición al rey de 500 escudos para la defensa de Daroca (ACA, Can., reg. 1384, f. 174r; Monzón, 23-02-1363).

57 Por ejemplo, en la orden de defensa de algunas aldeas de Calatayud en agosto de 1361, se dice que los lanceros tengan "pavés o escudo" (ACA, Can., reg. 1469, ff. 21v-22r; Barcelona, 25-12-1361); cuando en diciembre de 1362 se obliga al concejo de Cariñena que forme un depósito de material, se dice que debe poseer "ducientos pavezos ho scudos" (Gutiérrez de Velasco, 1961: 15, nota 24; ACA, Can., Reg., 1384, f. 159r; Monzón, 30-12-1362).

58 Véase Serrano, 1915a: 344 y 356 (nota 6): en un inventario zaragozano de 1374 vemos la expresión "scudos de almazen", en aragonés.

59 Alcover y Moll, 1978-1979, vol. V: 431, voz "espinac".

60 Por ejemplo, en la Estoria de España (siglo XIII): Gago-Jover, 2002: 15-16 y 106-107.

61 Ignoro el significado exacto del término.

62 El término utilizado, escopro, no es catalán sino aragonés; se encuentra en documentos aragoneses como el inventario del castillo de Sesa en 1274 (Durán Gudiol, 1956: 97) o alguno del Teruel bajomedieval (Terrado, 1991: 305). 
Además de las máquinas en sí, el inventario cita como elementos complementarios: 6 tablas que están cerradas y clavadas y tienen la finalidad de guardar y conservar los citados ingenios y trabucos; 12 vigas necesarias para la construcción de los ingenios.

Los recipientes mencionados son: 2 cajas y media de almacén; 3 tinas; un cubellet ${ }^{63} \mathrm{o}$ tina pequeña con sus círculos y accesorios; media rueda de tina (elemento desconocido); 8 cubas o botas situadas en serones con todos sus accesorios, a excepción sólo de una. Se citan igualmente 3 molinos de moler a mano con sus muelas (uno con su nadilla y 2 tolvas), un arca grande, 9 mesas largas, 6 escaleras dobles y 8 fanegas de sal de agua (tal vez salmuera).

\section{ANÁLISIS DE LAS MÁQUINAS DE GUERRA}

Dado que todos los ingenios estaban incompletos en mayor o menor medida, los inventarios describen lo que falta de ellos más que lo que poseen. Es probable que la mayoría estuvieran desmontados porque así se solían transportar (normalmente eran montados cuando entraban en uso) ${ }^{64} \mathrm{y}$ porque los inventarios nos dicen que faltaban muchos clavos, clavijas y hierros que serían necesarios para mantener cohesionadas las máquinas. Además, recordemos que el segundo inventario cita la presencia de 12 vigas necesarias para construir o montar los ingenios. El primer inventario menciona también dos carros para llevar los ginys, que se transportarían desmontados.

Como se ha visto, el Castillo Mayor poseía tres ginys (ingenios) y dos trabucos y el Castillo Real tenía seis ginys, un trabuco y una cabrita.

El tipo de artefacto mejor definido en las fuentes es el trabuco, que era una máquina de artillería con contrapeso fijo (figura 12); éste consistía en una caja, rellena con diversos tipos de materiales, que al bajar por su propio peso hacía girar la viga en cuyo extremo estaba atada la honda que alojaba el proyectil. Los trabucos poseen los siguientes componentes, según mencionan expresamente los inventarios (figura 11): el pie (peu), las cajas o contrapesos ( $c a-$ $x e s$ ), la canal (ranura inferior por la que se deslizaba la honda al ser proyectada y que permitía la orientación del disparo), el torno (que permitía bajar y tener sujeta la cuerda que bajaba la viga), las sogas, los hierros y clavijas (elementos que permitirían ensamblar y reforzar la estructura), pesas para pesar las piedras y mazos (éstos últimos para soltar el madero que mantenía sujeta la viga mediante una clavija o cuerda y permitir así el disparo). Algunos componentes esenciales, como la percha y la honda, no son citados en el texto, pero se sobreentiende que los poseen.

La mayor parte de las máquinas de guerra citadas en los inventarios reciben la denominación de giny ("ingenio"), que designa de modo genérico a una máquina de guerra. De los inventarios se deduce que con la palabra giny se está designando a un conjunto de máquinas muy parecidas entre sí y que a su vez se diferencian poco de los trabucos, pues los componentes citados son semejantes a los de éstos. Los inventarios citan como constitutivos de los ginys muchos elementos que también citan para los trabucos (hierros, clavijas, sogas, caja, canal, torno, pesas y mazos) pero mencionan otros dos más, la perxa (gran viga que al girar sobre un eje provocaba el lanzamiento del proyectil) y la fonda (honda), que también formarían parte

${ }^{63}$ Un cubellet es un cubell pequeño, y el cubell equivale a la tina: Alcover y Moll, 1978-1979, vol. III: 797 (voces "cubell" y "cubellet").

${ }^{6}$ Cuando Pedro IV emprendió la conquista del Rosellón mandó construir ingenios en Valencia y Barcelona que fueron transportados en naves; al llegar y desembarcar, fueron montados (Monreal, 1971: 23; 48-49, notas 51 y 52). 
de aquéllos (figura 11). Los inventarios indican que los ginys tenían un solo contrapeso fijo ${ }^{65}$, mientras que los trabucos tenían uno o dos; la cabrita poseía dos. Todas las máquinas eran por tanto de contrapeso fijo y estaban alejadas de las técnicas de tracción manual o de carácter híbrido. ${ }^{66}$

Parece que la única diferencia entre ginys y trabucos era la mayor simplicidad y menor tamaño de aquéllos, de lo que se derivaría una menor potencia y eficacia. La contraposición entre trabucos y ginys es frecuente en las Crónicas catalanas y otras fuentes catalanas de los siglos XIII y XIV (Llull, Eiximenis), citándose a veces algunos nombres de ginys concretos como el fonèvol, la brigola (figura 13) o el manganell de dues caixes. ${ }^{67}$

La cabrita del Castillo Real era una máquina de dos contrapesos, aunque éstos le faltaban. Las fuentes definen la cabrita como una máquina muy potente aunque no la describen físicamente. ${ }^{68}$ Nuestro inventario hace suponer que se parecería a los trabucos más grandes.

Un aspecto muy interesante y curioso ofrecido por los documentos analizados es la distinción de las máquinas de guerra mediante marcas o símbolos y algún nombre ("del Zorzo"). Dichas marcas podrían ser distintivos de autor o procedencia o simplemente servir para diferenciar e individualizar cada ingenio.

\section{CONCLUSIONES}

Los inventarios aquí analizados son documentos de un enorme valor al ser únicos para conocer el contenido de los castillos de Calatayud y a causa de su claridad y expresividad. Se suman a la corta lista de escritos de este tipo referentes a castillos aragoneses. ${ }^{69}$

Los inventarios no dicen nada sobre las estancias o la distribución interna de los edificios. La impresión general que dan sobre los objetos contenidos en los castillos es de escasez. Por una parte, las armas y piezas de arnés no son abundantes y presentan notables peculiaridades y disimetrías. Entre las armas sólo están representados los escudos (en gran cantidad), los viratones, los abrojos (arma no frecuente) y dos variedades de armas arrojadizas: los venablos, muy raros en la documentación, y los glavis o lanzas. Contradictoriamente, falta un objeto tan importante como la ballesta (el arma más usada por las tropas de a pie) pero el inventario incluye gran cantidad de proyectiles para ella (viratones). Las piezas de defensa corporal, por otra parte, no están registradas en cantidades equivalentes; por ejemplo, el Castillo Mayor posee un par de quijotes, de brazales y de zapatos de hierro pero con dos pares de guanteletes, dos lorigones y tres pares de grebas y de gorgueras; los elementos de cubrición de la cabeza, entre yelmos y capellinas, son siete. Falta, por otra parte, un elemento tan importante como la coraza, citada con frecuencia. ${ }^{70}$

65 Se sabe, sin embargo, que una variedad de giny llamada brigola se caracterizaba por poseer dos contrapesos (véase por ejemplo, Sáez Abad, 2007: 112).

66 Sobre todas estas tecnologías y máquinas véase: Monreal, 1971: 18-25 (especialmente); Finó, 1972; Hill, 1973; Nicolle, 2002; Sáez Abad, 2007: 97-112 (sobre todo); Chevedden, 1998; Viollet-le-Duc, 1993: 452-456.

67 Monreal, 1971: 19, 20, 21, 23, 25, 47 (notas 33, 36 y 37), 48-49 (nota 52), 49 (notas 53, 54 y 60), 50 (nota 62).

68 Zurita menciona la utilización de una cabrita en el sitio de Balaguer en 1413 y dice que lanzaba piedras de 8 quintales y provocaba grandes estragos (Zurita, 1967-1988, libro XII, caps. XXVI-XXVII). También se cita el empleo de cabritas en la Crónica de Alfonso XI (hacia 1344-1350) a propósito de los sitios de Lerma y Pliego (Cerdá, 1787: 310 y 468). En 1374, Pedro IV encargaba hacer una “cabrida” para la defensa de Molina (Benítez Martín, 1992: 182-183).

69 Sobre los inventarios medievales de castillos aragoneses, véase Cantos, $2012 \mathrm{~b}$

70 Por ejemplo, en el inventario del alcázar de Teruel de 1366 se registran 10 corazas, tanto de hierro como de cuero (ACA, RP, MR, Volúmenes, Serie General, 784, ff. 256rv). 
Existe además una cierta disimetría en el reparto de estos elementos: las piezas de defensa corporal y los viratones están sólo en el Castillo Mayor; las armas arrojadizas y los abrojos en el Castillo Real. Aunque se registran ya elementos de arnés hechos de láminas de metal, se siguen usando elementos de cuero (quijotes, grebas) y yelmos de madera (aunque dorados y con viseras metálicas).

Lo que hace verdaderamente excepcionales a estos inventarios es la presencia en ellos de una gran cantidad de máquinas de guerra (trece en total), con la descripción de todos sus componentes y símbolos, lo que apenas tienen paralelo en el panorama español. Eran todas de contrapeso fijo: además de 9 ginys, se documentan 3 trabucos y una cabrita.

El mobiliario es muy austero, ya que se registran sólo un arca grande y nueve mesas, además de recipientes para contener líquidos; las cubas se usarían para contener vino, alimento muy usual en la época, aunque también pudieron usarse para vinagre u otros líquidos como aceite. Se documentan también los molinos para moler el grano.

La impresión general es no sólo de escasez sino también de dejadez y precariedad: muchos de los objetos están rotos o incompletos (capellinas, lanzas, máquinas de guerra, recipientes, molinos).

A pesar de todo, la importancia de los inventarios es enorme, al darnos el único fresco existente del contenido completo de los castillos y ofrecernos un despliegue impresionante de máquinas de guerra.

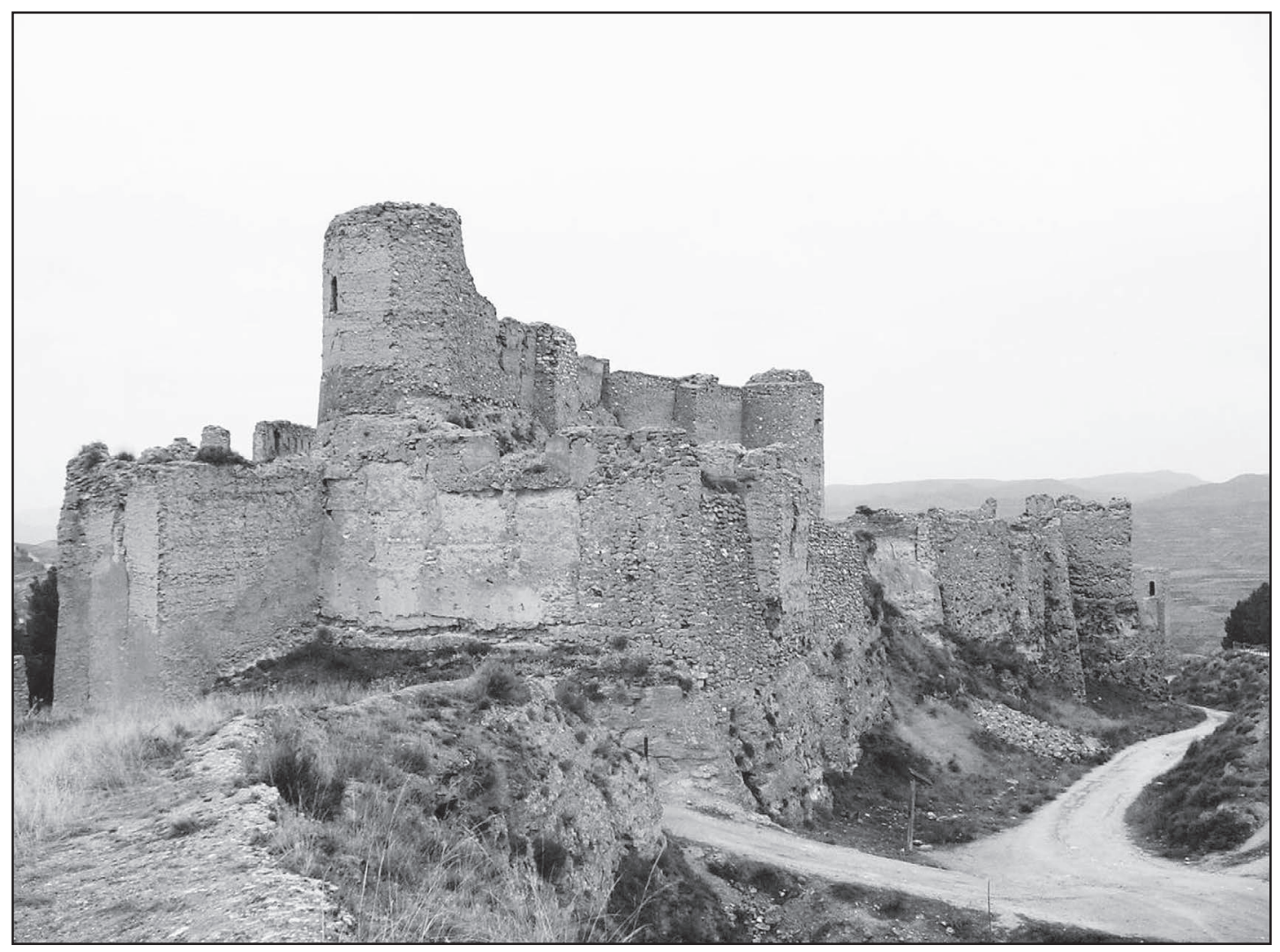

Figura 1. Vista del Castillo Mayor de Calatayud desde el Este antes de la restauración. 


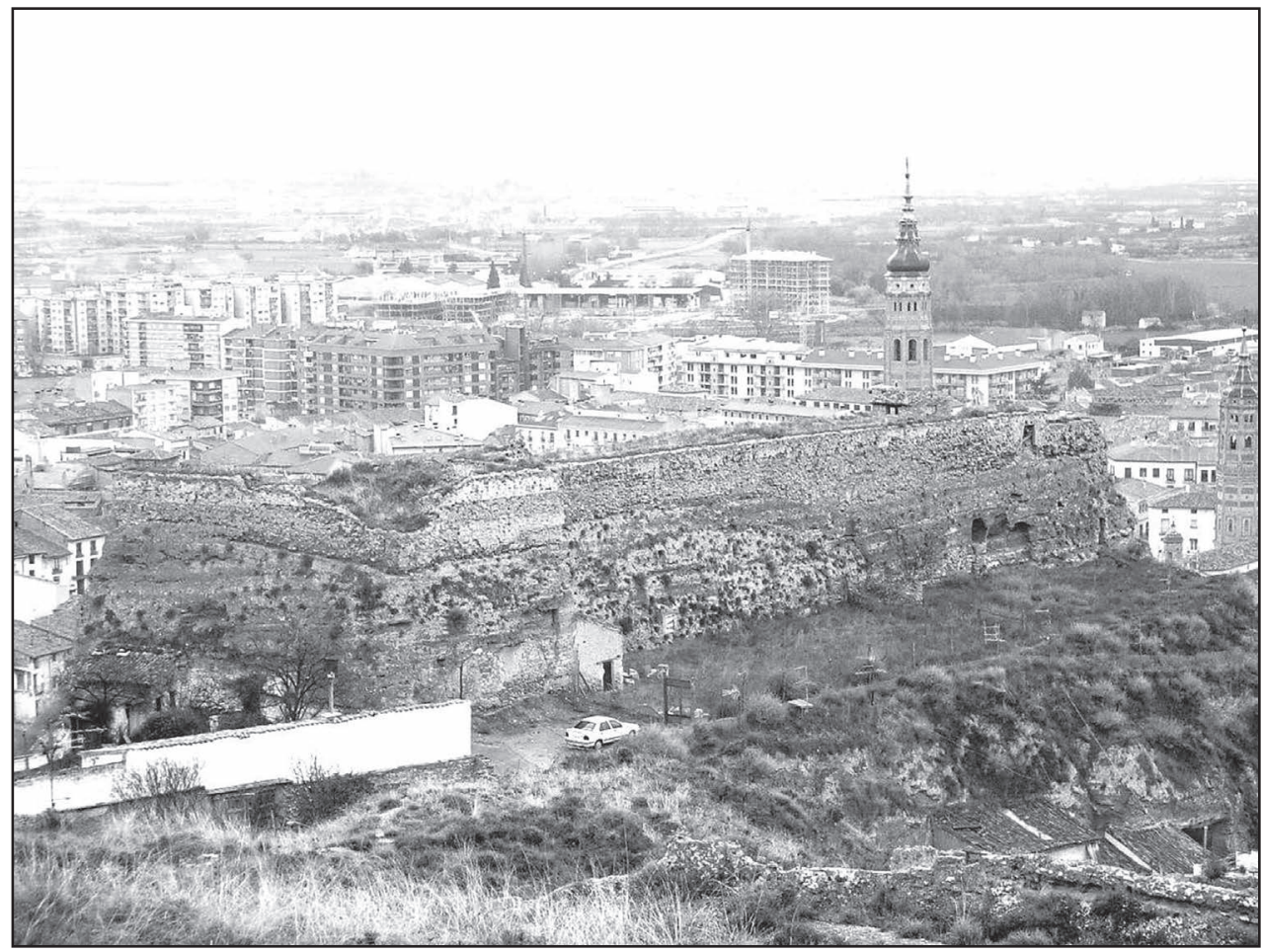

Figura 2. Vista del Castillo Real de Calatayud desde el Noreste.

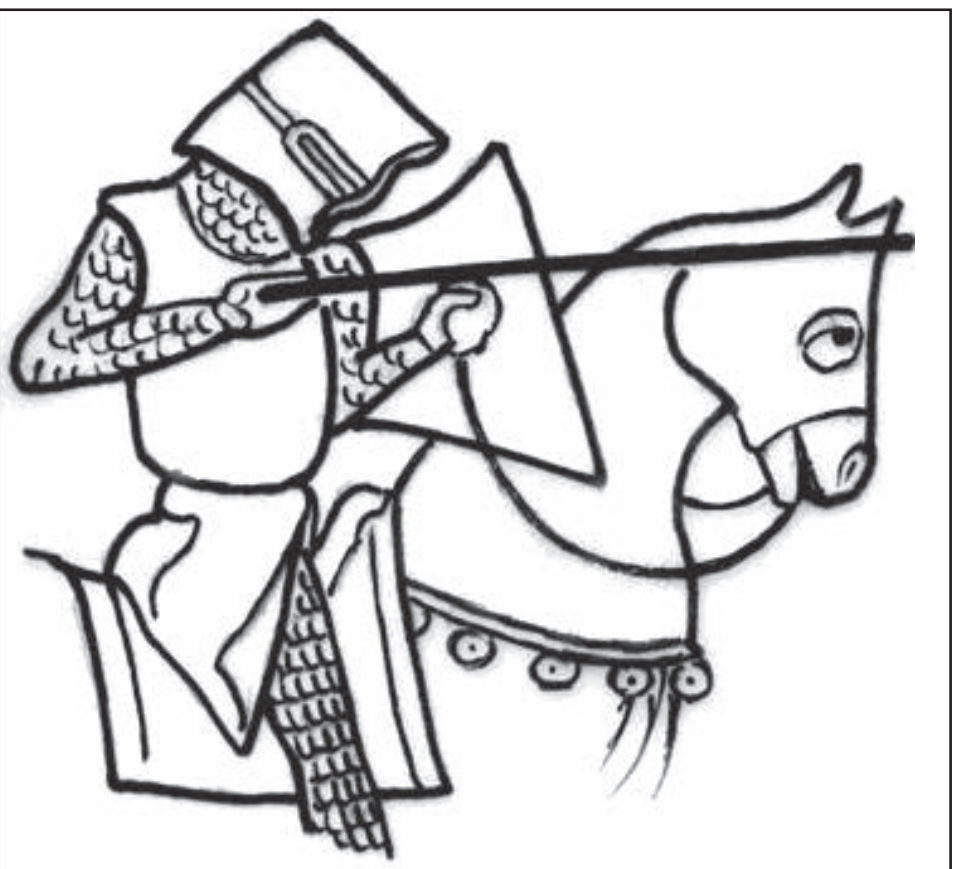

Figura 3. Caballero con ausberg (loriga), escudo, lanza y yelmo cilíndrico típico del siglo XIII. Techumbre de la catedral de Teruel; último tercio del siglo XIII. 


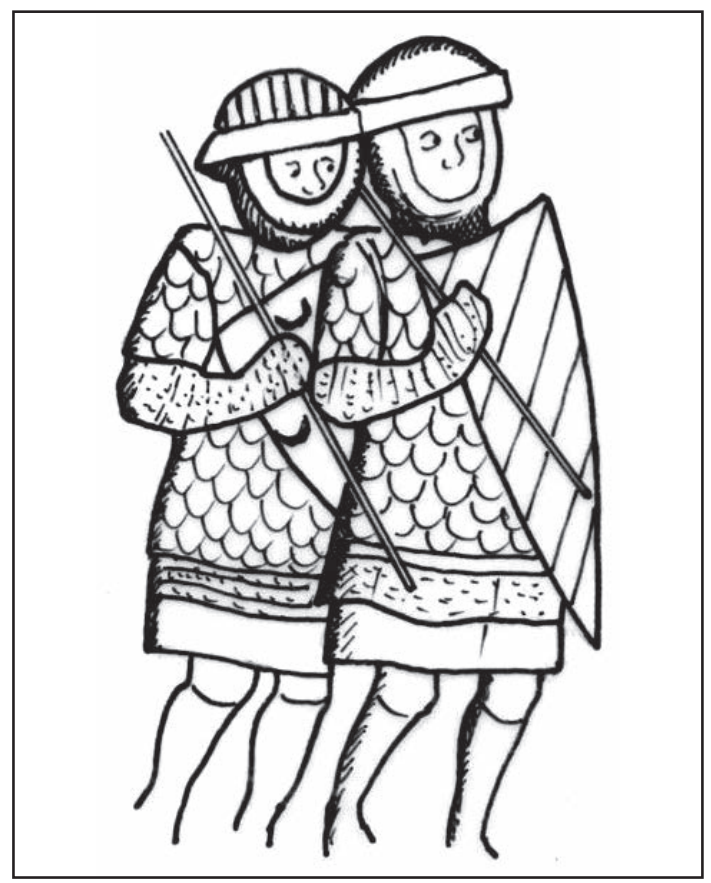

Figura 4. Soldados representados en uno de los códices de las Cantigas de Santa María (segunda mitad del siglo XIII): muestran lorigones con escamas superpuestos a la loriga y cubren la cabeza con capacetes; portan además escudo de tipo pavés y lanza.

Figura 6. Guerrero representado junto a la puerta de San Ivo de la catedral de Barcelona (hacia 1300). Se cubre con ausberg (loriga) y capacete; muestra ya elementos metálicos de protección de la pierna: gamberes o cameres (grebas) y sabates de ferre (escarpes o zapatos de hierro).

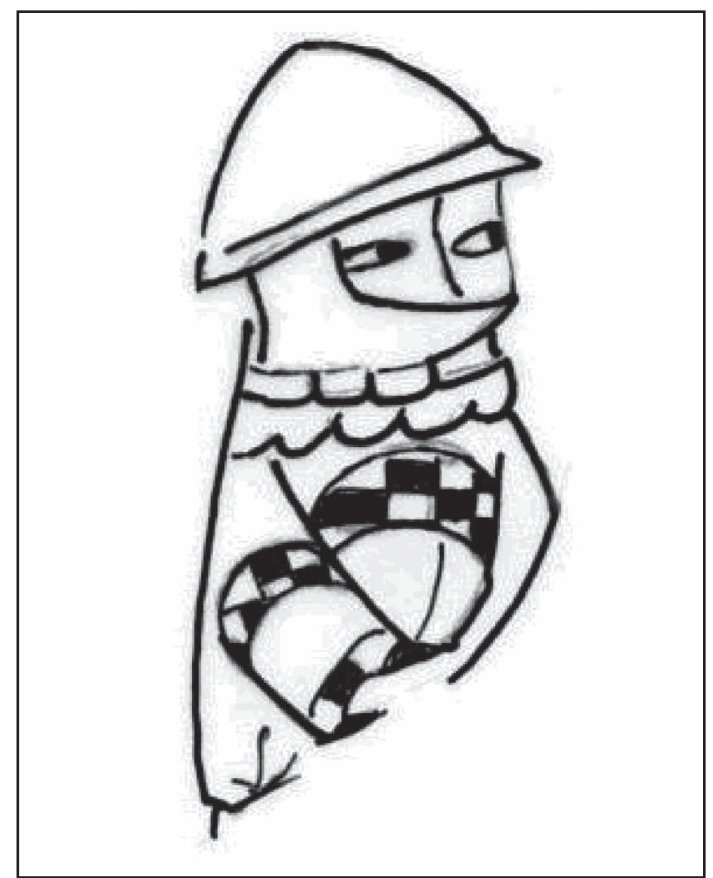

Figura 5. Caballero representado en las pinturas de la torre del homenaje del castillo de Alcañiz (Teruel); cubre la cabeza con capacete sobre el capmall. Último decenio del siglo XIII o primero del siglo XIV.

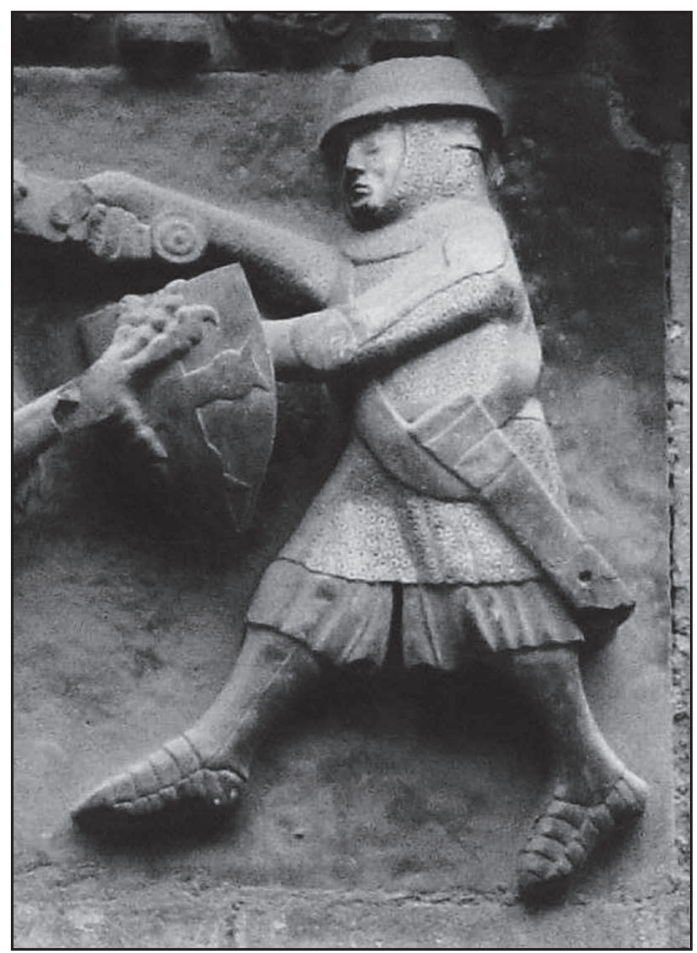




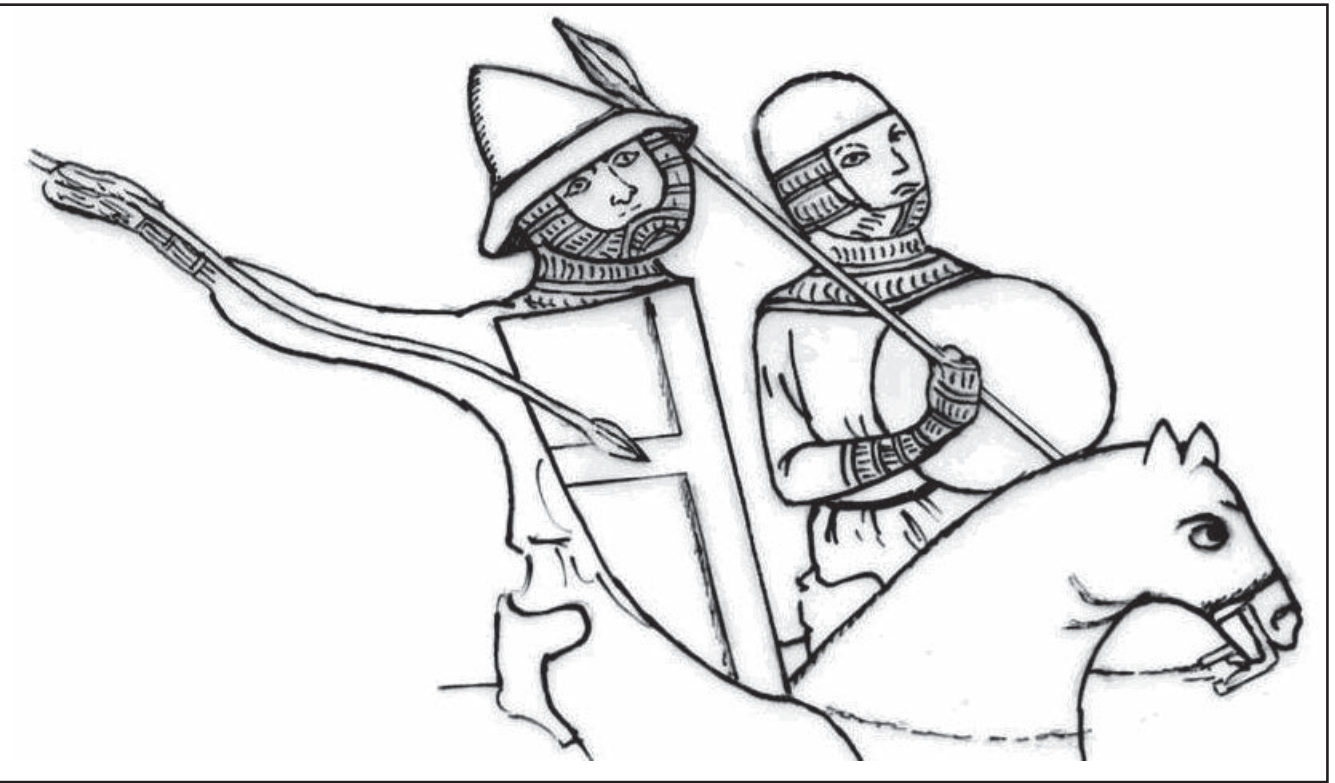

Figura 7. Caballeros representados en las pinturas murales de Santa Lucía de Sos del Rey Católico (Zaragoza) (primeras décadas del siglo XIV). Muestran loriga, lanza y escudo. El de la derecha cubre la cabeza con una capellina y el de la izquierda con un capacete.

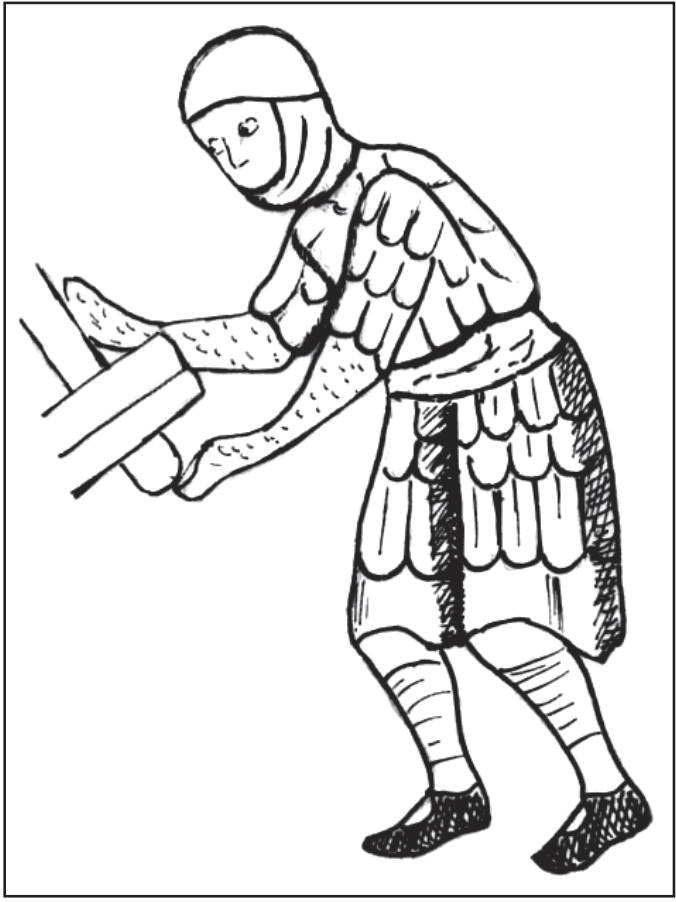

Figura 8. Soldado de a pie representado en uno de los códices de Las Cantigas de Santa María (segunda mitad del siglo XIII). Cubre la cabeza con capellina y el cuerpo con lorigón de escamas.

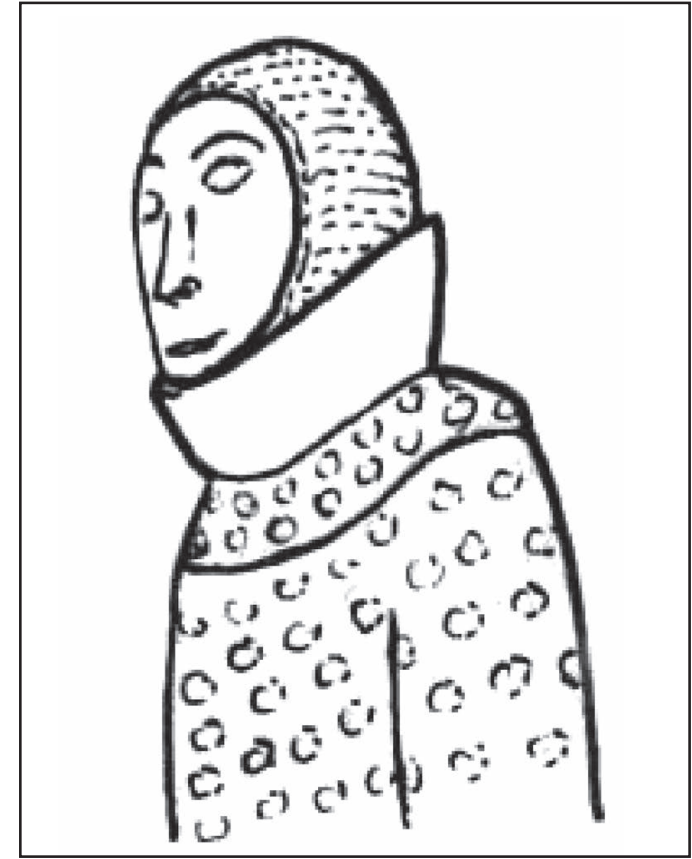

Figura 9. Parte superior (colocada en vertical) de la escultura yacente de Àlvar de Cabrera, vizconde de Ager, datada entre 1299 y 1314 (actualmente en The Cloisters de Nueva York, aunque procedente de Bellpuig de les Avellanes). Muestra un buen ejemplo de gorguera al cuello. 


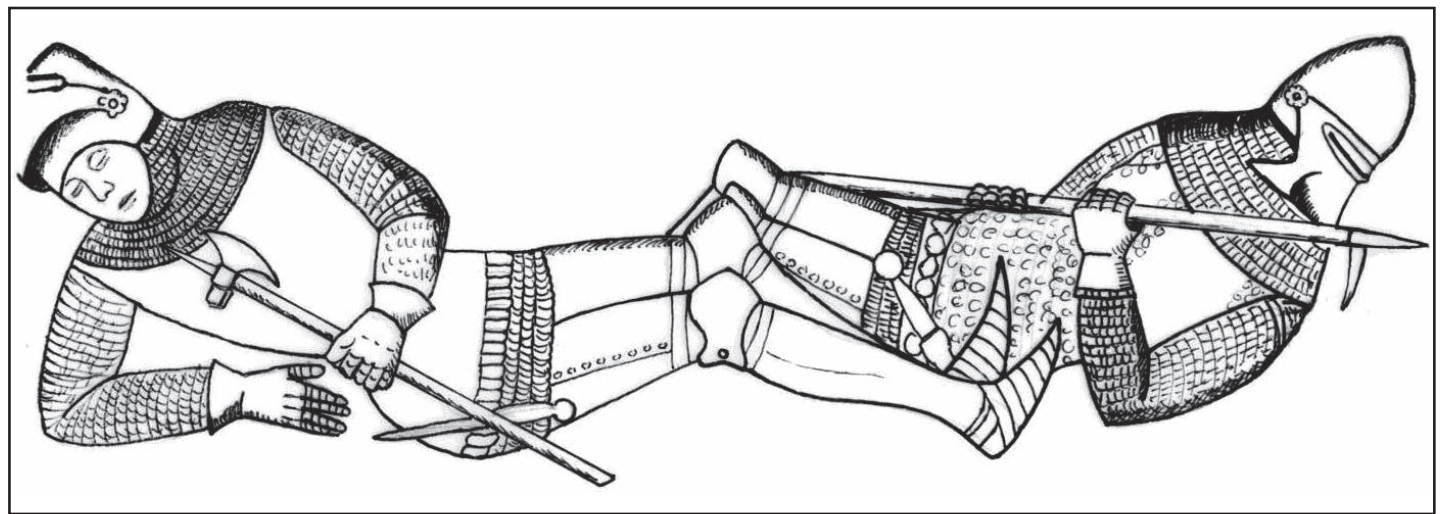

Figura 10. Detalle de la escena de la resurrección de Cristo en el retablo de la Virgen del Monasterio de Sijena (Huesca) (1367-1381); actualmente en el Museo Nacional de Arte de Cataluña. Los dos soldados visten al interior ausbergs (lorigas) y cubren manos y extremidades inferiores con elementos de arnés metálico: guants de launa (guanteletes), cuxots o cuxeras (quijotes), cameres o gamberes (grebas), sabates de ferre (escarpes o zapatos de hierro). Cubren la cabeza con bacinetes con visera y portan una especie de alabardas pequeñas.

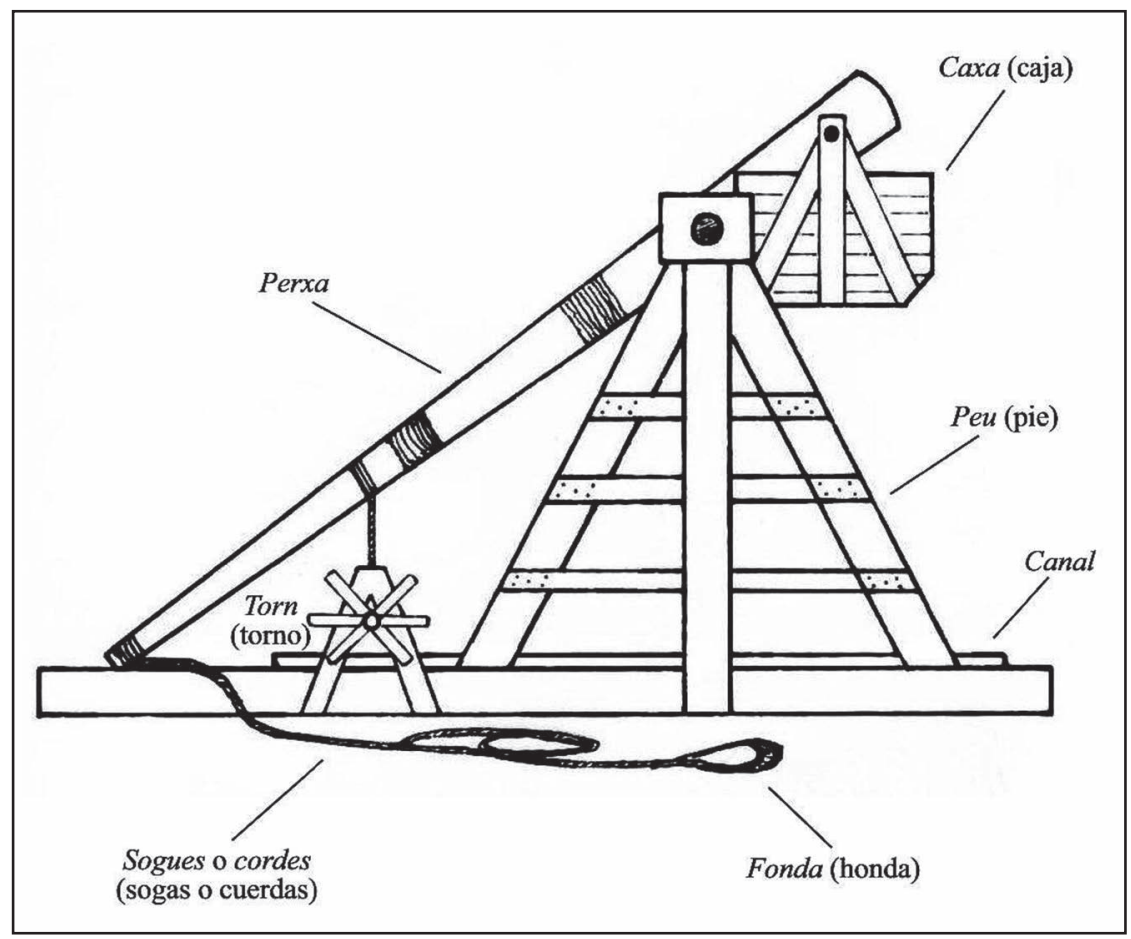

Figura 11. Representación ideal de uno de los trebuchs (trabucos) o ginys (ingenios) citados en los inventarios de Calatayud con indicación de sus componentes principales según la terminología empleada en dichos inventarios. 


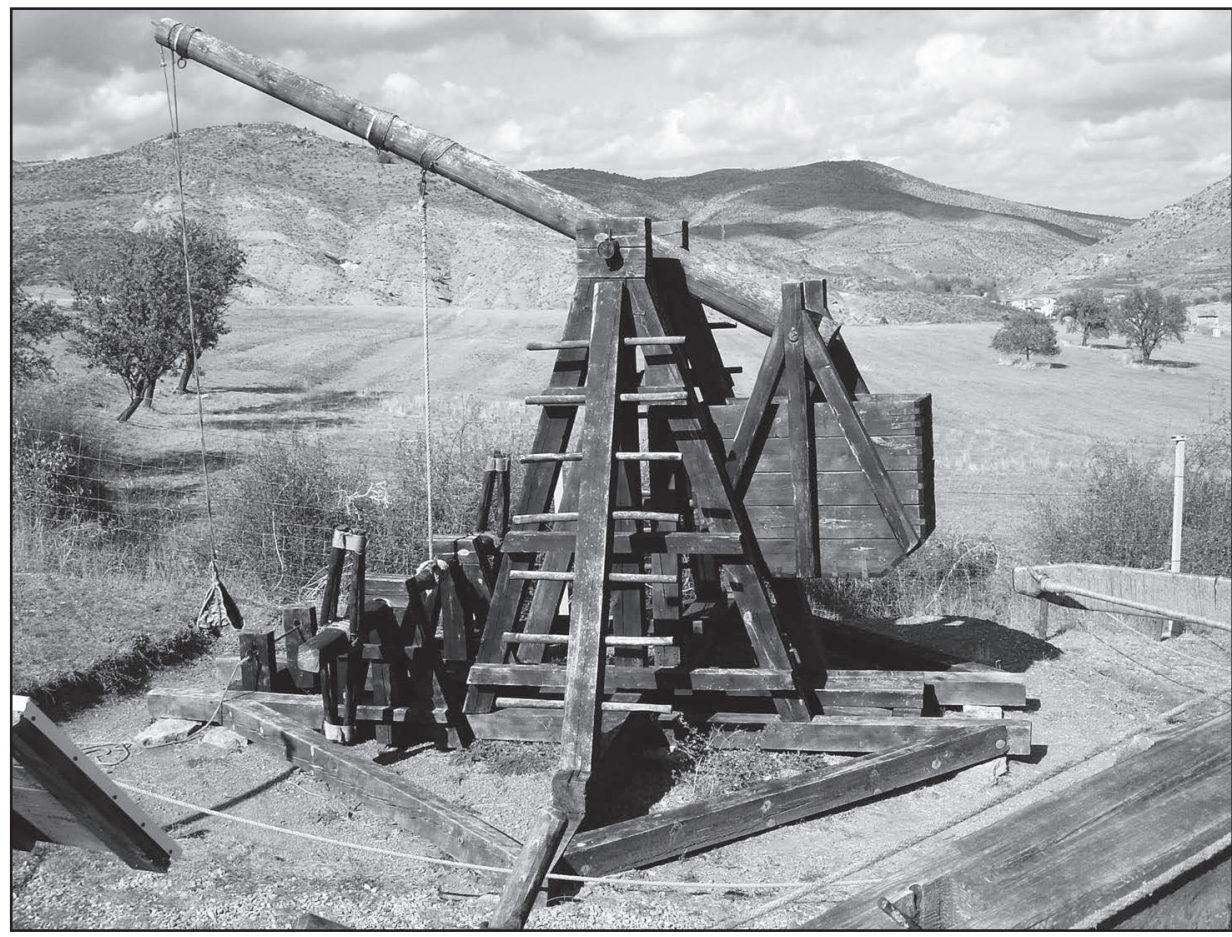

Figura 12. Reconstrucción de trabuco medieval; a la izquierda se ve la honda y el torno y a la derecha el contrapeso. Trebuchet Park, Albarracín (Teruel).

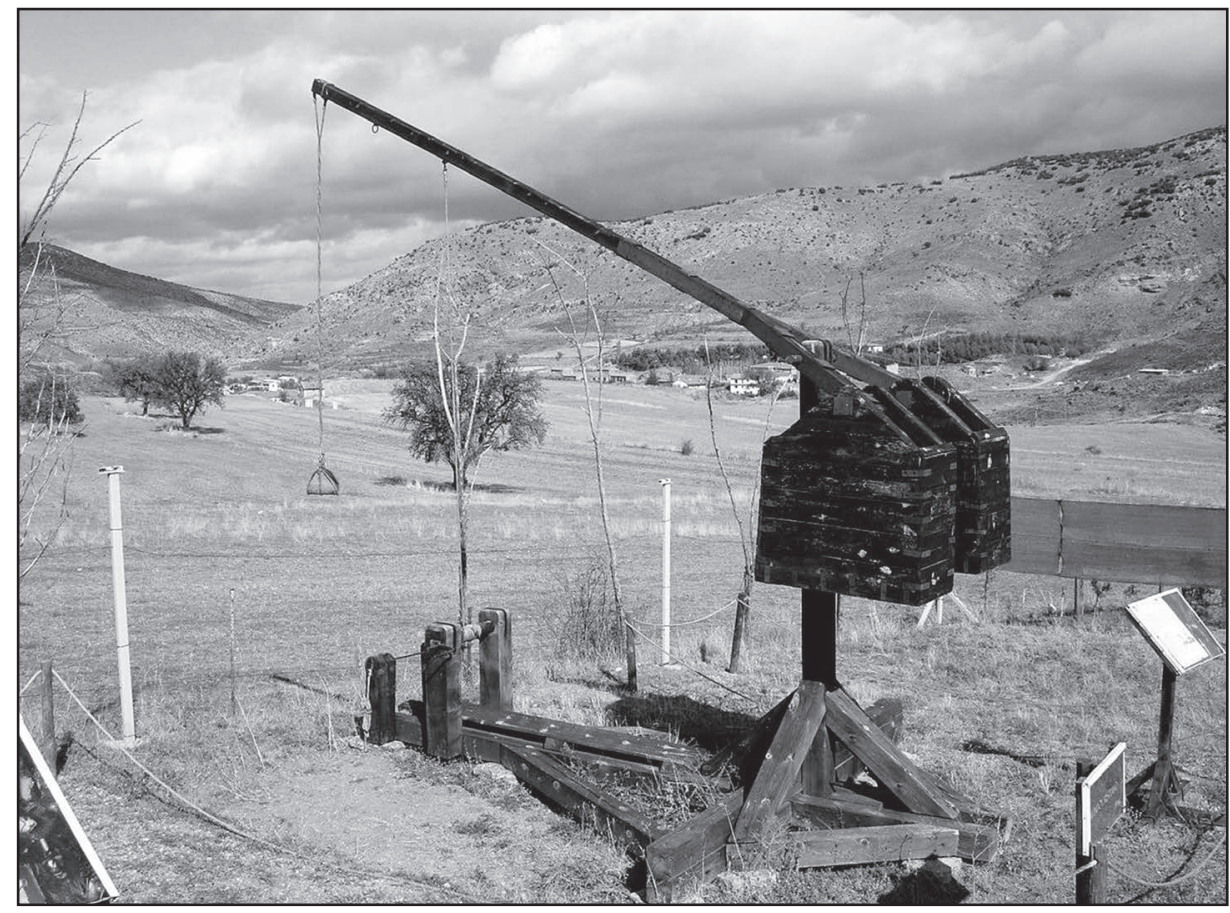

Figura 13. Reconstrucción de brigola de dos cajas o contrapesos, uno de los ingenios (ginys) citados en las fuentes medievales. Trebuchet Park, Albarracín (Teruel). 


\section{BIBLIOGRAFÍA}

Alcover, A. M. y Moll, F. de B. (1978-1979): Diccionari català-valencià-balear. Palma de Mallorca, ed. Moll.

Almirante y Torroella, J. (1989): Diccionario militar. Madrid, Ministerio de Defensa, Secretaría General Técnica.

Alós-Moner i de Dou, R. d' (1910): «Inventaris de castells catalans (segles XIV-XVI). Inventaris de Tous (1372-1410)». Estudis Universitaris Catalans, 4: 131-192.

Batlle, C. y Parés, À. (1986): «El castell de Sitges a la mort de Bernat de Fonollar (1326)». Fortaleses, torres, guaites $i$ castells de la Catalunya medieval, Acta historica et archaeologica mediaevalia, Annex 3: 153-177. Barcelona, Universidad de Barcelona.

Benítez Martín, L. (1992): Documentos para la historia de Molina en la Corona de Aragón: 1369-1375 (El registro 1551 de la Cancillería de Pedro IV). Zaragoza, Institución Fernando el Católico.

Betí, M. (1914): «Un inventari del Castell de Penyíscola, any 1451». Estudis Universitaris Catalans, 8: 92-102.

Bruhn de Hoffmeyer, A. (1982): Arms and armour in Spain. A short survey. Vol. II. From the end of the 12 th century to the beginnings of the 15th century. Número monográfico de Gladius. Madrid, Instituto de Estudios sobre Armas Antiguas, Consejo Superior de Investigaciones Científicas.

Calahorra, P. (2000): «Memorial de los bienes que fueron del ilustrísimo señor don Juan [I], arçobispo de Çaragoça, que fueron fallados en la guardaropa de las casas archiepiscopales». Aragón en la Edad Media, 16: 129-144.

Cantos, A. (2012a): «Las fortificaciones de la villa de Calatayud en los inicios de la Guerra de los dos Pedros (septiembre 1356-mayo 1357)». Ruibal, A. (coord.), Actas del IV Congreso de Castellología, Madrid, 7 a 10 de marzo de 2012, Madrid, Asociación Española de Amigos de los Castillos: 199-204.

Cantos, A. (2012b): «Fuentes para el conocimiento de la vida cotidiana en los castillos aragoneses de la Baja Edad Media (ss. XIII a XV)». Construcciones para vivir y combatir. V Jornadas de Castellología Aragonesa, Calatorao, 5 a 7 de noviembre de 2010. Zaragoza, Asociación para la Recuperación de los Castillos de Aragón e Iniciativa Cultural Barbacana: 189-259.

Cantos, A. (2014a): «Las fortificaciones de Calatayud en el tercer cuarto del siglo XIV. Aproximación a su historia, dirección, reparaciones y armamento». Patrimonio Cultural del Valle del Ebro (Historia, Cultura, Arte y Paisaje), 4: 7-39.

Cantos, A. (2014b): «Las fortificaciones aragonesas durante la Guerra de los Dos Pedros». Las fortificaciones en guerra. VI Jornadas de Castellología Aragonesa (Calatorao, 9, 10 y 11 de noviembre de 2012), Zaragoza, Asociación para la Recuperación de los Castillos en Aragón e Iniciativa Cultural Barbacana: 135-200.

Cerdá y Rico, F. (ed.) (1787): Crónica de Don Alfonso el onceno de este nombre, de los reyes que reynaron en Castilla, Madrid, Imprenta de Don Antonio de Sancha.

Chevedden, P. E. (1998): «The Hybrid Trebuchet: The Halfway Step to the Counterweight Trebuchet». Kagay, D. J. y Vann, T. M., On the Social Origins of Medieval Institutions: Essays in Honor of Joseph F. O' Callaghan, Leiden-Boston-Colonia, Ed. Brill: 179-222.

Durán Gudiol, A. (1956): «Notas de archivo». Argensola, 25: 93-101.

Fernández Clemente, E. (dir.) (1980-2007): Gran Enciplopedia Aragonesa, Zaragoza, Unión Aragonesa del Libro.

Finó, J.-F. (1972) : «Machines de jet médiévales». Gladius, X: 25-44.

Gago-Jover, F. (2002): Vocabulario militar castellano (siglos XIII-XV). Granada, Editorial Universidad de Granada.

Gutiérrez de Velasco, A. (1961): «Las fortalezas aragonesas ante la gran ofensiva castellana en la guerra de los dos Pedros». Cuadernos de Historia Jerónimo Zurita, 12-13: 7-39.

Hill, D. R. (1973): «Trebuchets». Viator 4: 99-115.

Lacarra Ducay, Ma del C. (1978): «Pinturas murales en Santa Lucía de Sos del Rey Católico (Zaragoza)». Principe de Viana, 152-153: 483-496.

Lafuente Gómez, M. (2009): «La crisis del siglo XIV en Calatayud y sus aldeas: el factor de la guerra». VII Encuentro de Estudios Bilbilitanos (Calatayud, 28 a 30 de abril de 2006), Calatayud, Centro de Estudios Bilbilitanos e Institución Fernando el Católico, tomo II: 109-121. 
Lafuente Gómez, M. (2013): «Categorías de combatientes y su armamento en el Aragón bajomedieval: la Guerra de los dos Pedros (1356-1366)». Gladius, XXXIII: 131-156. http://dx.doi.org/10.3989/ gladius.2013.0006

Leguina y Vidal, E. de (1912): Glosario de voces de armería. Madrid, Librería de Felipe Rodríguez.

Miret i Sans, J. (1911): «Inventaris de les cases del Temple de la Corona d'Aragó en 1289». Boletín de la Real Academia de Buenas Letras de Barcelona, 42: 61-75.

Monreal y Tejada, L. (1971): Ingeniería militar en las crónicas catalanas. Discurso de ingreso leído el día 31 de enero de 1971 en la Real Academia de Buenas Letras, Barcelona.

Nicolle, D. (2002): Medieval Siege Weapons (1). Western Europe A.D. 585-1385. Oxford, Osprey Publishing Ltd.

Riquer, M. de (1968): L'arnés del cavaller. Armes i armadures catalanes medievals. Barcelona, Edicions Ariel.

Rodrigo Estevan, M. L. (1999): La ciudad de Daroca a fines de la Edad Media : selección documental (1328-1526). Daroca, Centro de Estudios Darocenses, Colección Documentos para la historia de Daroca y su Comunidad, 3.

Rovira i Port, J. y Casanovas i Romeu, À. (2014): Las pinturas murales medievales del castillo calatravo de Alcañiz. Alcañiz, Centro de Estudios Bajoaragoneses.

Sáez Abad, R. (2007): Artillería y poliorcética en la Edad Media. Madrid, Almena.

Serrano y Sanz, M. (1915a): «Inventarios aragoneses de los siglos XIV y XV. III». Boletín de la Real Academia Española, 2: 341-352.

Serrano y Sanz, M. (1915b): «Inventarios aragoneses de los siglos XIV y XV. IX». Boletín de la Real Academia Española, 2: 708-709.

Serrano y Sanz, M. (1917): «Inventarios aragoneses de los siglos XIV y XV. LIII». Boletín de la Real Academia Española, 4: 520-521.

Sesma Muñoz, J. A. y Líbano Zumalacárregui, Á. (1982): Léxico del Comercio Medieval en Aragón (siglo XV). Zaragoza, Institución Fernando el Católico.

Soler del Campo, Á. (1993): La evolución del armamento medieval en el reino castellano-leonés y alAndalus (siglos XII-XIV). Madrid, Servicio de Publicaciones del EME.

Terrado, J. (1991): La lengua de Teruel a fines de la Edad Media. Teruel, Instituto de Estudios Turolenses, Excma. Diputación Provincial de Teruel.

Tomás Faci, G. (2009): «Distinción social en el seno de la baja nobleza aragonesa: el palacio de los Zapata de Calatayud en 1484». Anuario de Estudios Medievales, 39 (2): 605-629. http://dx.doi. org/10.3989/aem.2009.v39.i2.117

Viollet-le-Duc, E. (1993): Encyclopédie médiévale. Tome 1, Architecture. Inter-Livres, D.L.

Wittlin, C. J. (1976): «Un inventario turolense de 1484: Los Sánchez Muñoz, herederos del papa Clemente VIII». Archivo de Filología Aragonesa, 18-19: 187-216.

Zurita, J. (1967-1988): Anales de la Corona de Aragón. Edición de A. Canellas López, Zaragoza, Institución Fernando el Católico.

Recibido: $22 / 06 / 2015$

Aceptado: 20/04/2016 


\title{
APÉNDICE
}

\author{
ACA, RP, MR, 788, ff. 4v-5r
}

27 de febrero de 1371. Inventario de bienes muebles del Castillo Mayor de Calatayud, entregados por Bernat Arloví a los alcaides Jaime Pérez de Azúa y Gil Martínez Civera.

Jacme Pérez d'Azúa, Gil Martínez Civera. Alcayts del castell maior de la ciutat de Calataiud.

Appar per I $\mathrm{I}^{\mathrm{a}}$ carta pública feta e aclosa per en Pasqual Assensio, vehí de la dita ciutat de Calataiud e notari públic per autoritat reyal en tot lo Regne d'Aragó, lo XXVII dia del mes de febrer del any de la nativitat de nostre senyor MCCCLXXI, restituida per en Bernat Arloví, escrivà del senyor Rey, per rahó de I compte per ell recut al Mestre Racional de la cort del dit senyor de diverses comissions Reyals a ell fetes en lo dit Regne d'Aragó en los anys de la Nativitat de nostre senyor MCCCLXX, LXXI e MCCCLXXII. Que per lo dit en Bernat Arloví, axí com a comissari dessús dit, foren regonegudes totes les armes e furniments qui eren en lo dit castell maior de la dita ciutat. E foren hi trobades les armes e furniments davall contenguts, los quals, segons que en la dita carta pública és contengut, foren livrades e comanades per lo dit en Bernat Arloví als dits alcayts qui aquells furniments e armes atorgaren haver hauts e reebuts del dit en Bernat e tenir en comanda e depòsit, axí com alcayts dessús dits, per part e en nom de la cort del senyor Rey. E són les dites armes e furniments aquestes que 's seguexen. E primerament IIII elms de fust oripellats ab les cares de ferre. Ítem, XXV escuts a senyal de Sentiago. Ítem, II lorigons. Ítem, II parells de cameres de ferre. Ítem, III capellines de ferre trencades. Ítem, I parells de cuxots e cameres de cuyr. Ítem, III gorgeres de ferre. Ítem, uns braçals de ferre. Ítem, I I contera de portar bandera. Ítem, II parells de guants de launa. Ítem, I parell de sabates de ferre. Ítem, I ${ }^{\mathrm{a}}$ creu de ferre per al front del cavall. Ítem, LXXIIII caxes de viratons genoveschs molt bons. E en cascuna caxa ne havia $\mathrm{D}$, que munten los dits viratons a XXXVI mille viratons. Ítem, XXXVII costals de caxes de viratons qui no eren tan bons com los dessús dits, e havia en cascun costal IIII caxes e en cascuna caxa CC viratons, e són CXLVIII caxes qui fan XXVIII mille DC viratons. Ítem, XLVI caxas de viratons e en cascuna caxa havia D viratons, perquè eren XXIII mille viratons. Ítem, III caxes grans de viratons e en cascuna caxa havia MCCC viratons, perquè eren III mille DCCCC viratons. E axí són en summa totes les dites caxes de viratons CCLXX caxes. E munten en summa tots los dits viratons XCII mille D viratons. Ítem, $\mathrm{I}^{\mathrm{a}}$ tina e $\mathrm{I}^{\mathrm{a}}$ bóta ab lurs cercles. Ítem, $\mathrm{I}^{\mathrm{a}}$ soga gran e $\mathrm{I}^{\mathrm{a}}$ fonda de giny noves de cànem. Ítem, $\mathrm{I}^{\mathrm{a}}$ altra tina ab sos cercles. Ítem, I tinell que no havia compliment de cercles. Ítem, III molins parats ab lurs muellas, vadillas (sic) e tolvas. Ítem, I altre molí ab muellas menys de ferres. Ítem, I giny del escut blanch del qual fallen los claus capdals o ferres e la perxa que fa encara acabar e encara hi fallen les coses siguents. Es a saber, la canal e XXX mederos del torns e tots lo ferres menuts e los parales e les sogues o cordes e lo pestell de la caxa. Ítem, I altre giny de la vanera de Sentiago, del qual fallen tots los ferres menuts e les sogues, e de tot l'als hi ha compliment. Ítem, I altre giny xiquet qui estava dins la vila de Calataiud com estava assetjada, en lo qual ha senyal de creu e és complit e aparellat de tirar exceptat que·n fallen les sogues o cordes e los ferres menuts. Ítem, I trebuch qui fo portat de Villaroya, lo qual és complit exceptat que $n$ fallen les sogues o cordes e X maderos de la caxa e los ferres menuts. Ítem, I altre trebuch qui·s anomena del Zorzo, del qual fallen les coses siguents. És a saber, lo peu e I ferre on estan les caxes e X maderos de les caxes e tots los ferres menuts e les sogues e cordes e lo torn ab tot son pertret, e allò matex fall de tots los dits ginys e trebuchs, e encara totes les taules de les caxes e clavilles e maços que han mester tots los ginys, e aximatex hi fallen III peses de pesar les pedres e les canals dels dits trebuchs. Ítem, II carros per portar los ginys, e lo I és guarnit e en l'altre no són sinó les rodes. Ítem, IIII cubas o bótes, la I a ab VII cercles, l'altra ab X cercles, l'altra ab IX, l'altra ab VIII cercles, ab tots lurs furniments de portes o cadiretes e serons en que estan. E axí a memòria és fet lo present notament als dits alcayts de totes les coses dessús contengudes. Ço és, que tota vegada que $n$ sien demanats e requests ne donen compte e rahó a la cort del senyor Rey. La qual carta a cautela de la dita cort fo mesa e conservada en lo coffret vermell d'en Berenguer de Relat, Mestre Racional qui està en son offici. 


\section{ACA, RP, MR, 788, ff. 5r-6v}

26 de febrero de 1371. Inventario de bienes muebles del Castillo Real de Calatayud, entregados por Bernat Arloví a los alcaides Pedro Gilbert Bru y Andrés de Cevamanos.

Pero Gilbert Bru, Andrez de Cevamanos. Alcayts del Castell Reyal de la ciutat de Calataiud.

Ítem, appar per I $\mathrm{I}^{\mathrm{a}}$ altra carta pública feta e aclosa per lo dit Pasqual Assensio, notari, lo XXVI dia del mes de febrer del any de la Nativitat de nostre senyor MCCCLXXI, restituida per lo dit en Bernat Arloví per la raó en lo prop escrit dessús notament expresada, que per lo dit en Bernat foren livrades e comanades als dits alcayts les armes e furniments davall contenguts, los quals foren atrobats en lo dit castell Reyal de la dita ciutat de Calataiud e los quals són contenguts e espressats largament e discierta en la dita carta pública, ab la qual los dits alcayts atorguen haver aquells hauts e reebuts del dit en Bernat Arloví. E són los dits furniments e armes aquests qui·s seguexen. Primerament, IIII venables. Ítem, IIII barres de glavis sens ferres. Ítem, XI escuts, los IIII a senyal de Sentiago los IIIII (?) negres o morenos e la I blanch, e l'escut que és blanch és orlat a la redor e I banda per lo mig e IIII angelets daurats, e l'altre escut dels dits XI és a senyal de veras e II castells. Ítem, V escuts d'almatzem, axí que són en summa tots los dits escuts XV. Ítem, $\mathrm{I}^{\mathrm{a}}$ caxeta ab espinachs de ferre. Ítem, I arcaç gran. Ítem, II caxes e miga d'almatzem. Ítem, VIII fanecas de sal d'aygua. Ítem, III molins de molre a mà ab lurs muellas e lo I ab sa nadilla e ab II tolvas. Ítem, IX taules largues. Ítem, III tinas e en la I ha IIII cercles, l'altra ne ha V, l'altra III cercles. Ítem, I cubellet o tina ab sos cercles ab tot son furniment. Ítem, miga roda de tina. Ítem, $\mathrm{I}^{\mathrm{a}}$ soga de giny. Ítem, $\mathrm{I}^{\mathrm{a}}$ cuba de VIII cercles. Ítem, $\mathrm{I}^{\mathrm{a}}$ cuba gran ab VII cercles. Ítem, $\mathrm{I}^{\mathrm{a}}$ altra cuba gran ab altres VII cercles. Ítem, I ${ }^{\mathrm{a}}$ altra cuba ab XI cercles. Ítem, I altra cuba ab VI cercles. Ítem, $\mathrm{I}^{\mathrm{a}}$ cuba ab VIII cercles. Ítem, I a altra cuba ab IX cercles. Ítem, I a altra cuba ab X cercles, les quals cubas o bótes estaven assetiades en lurs serons ab tot lur furniment exceptat solament la $\mathrm{I}^{\mathrm{a}}$. Ítem, un trebuch de las senyales de III colpes e I ${ }^{a}$ deffra de carpenteria, e fall d'aquest trebuch tot lo pertret del torn; encara fall del dit trebuch les sogues o cordes e los ferres on estan les caxes; encara fallen del dit trebuch V mederos de les caxes e totes les sogues o cordes que y són necessàries, e tot l'als hi és. İtem, I giny qui ha senyal de Ia estela, del qual giny fallen los ferres capdals e les sogues o cordes que y són mester e les clavilles e los altres claus menuts, e encara les taules de la caxa, e tot l'als hi és. Ítem, I altre giny qui ha per senyal III colps de I escopro e a la altra part ha per senyal de clau de ballesta e Ia $\mathrm{O}$, en lo mig del qual giny fall ço qui $\cdot \mathrm{s}$ seguex. Ço és, abdosos los ferres capdals e tots los altres ferres, clavilles e claus menuts e totes les sogues e cordes que y són necessàries e totes les taules de la caxa del dit giny que y són necessàries. Ítem, I altre giny en que ha I escut e en lo mig I ${ }^{\mathrm{a}}$ vanera de Sent Jacme, del qual giny fallen les coses siguents. Ço és, lo ferre de la caxa e tots los altres ferres menuts e totes les sogues [tachado: e ferres] o cordes que y són necessàries e totes les taules que són mester a la caxa, e tot l'als hi és. Ítem, I altre giny qui ha per senyal I escut e I lop en mig del dit escut, del qual giny fallen les clavilles e tots los altes ferres menuts e totes les cordes que ha mester e totes les taules de la caxa. Ítem, I altre giny que ha per senyal I pinya, del qual giny fallen tots los claus menuts e totes les taules de la caxa e totes les clavilles de cordes necessàries al dit giny, e tot l'als hi es. Ítem, I altre giny en lo qual ha I escut e en lo mig del escut ha I senyal de ala, lo qual giny està per aplanar e reyatar, del qual giny fallen totes les clavilles e tots los claus menuts e totes les cordes a aquell necessàries e totes les taules de la caxa, e tot l'als hi és. Ítem, $\mathrm{I}^{\mathrm{a}}$ cabrita la qual ha per senyal II formes de sabates, la qual cabrita encara no es acabada de fer e fallen ne les caxes. Item, VI escales dobles. Ítem, VI taules qui estan fermades e clavades per guarda e salvament dels dits ginys e trebuchs. Ítem, XII bigas que són necessàries als dits ginys com se bastexen. E axí a memòria és fet açí lo present notament als dits alcayts de totes les armes e furniments dessús contenguts. Co és, que tota vegada que $n$ sien requests ne donen compte e rahó a la cort del senyor Rey. E és cert que la dita carta pública en la qual, segons que dit és, se contenen totes les dessús dites coses largament e discierta, fo mesa e conservada a cautela de la dita cort en lo coffret vermell del dit en Berenguer de Relat, Mestre Racional, lo qual és dins son offici. 